\title{
TIMAP Upregulation Correlates Negatively with Survival in HER2- Negative Subtypes of Breast Cancer
}

\author{
Marya Obeidat ${ }^{1 *}$, Khaldon Bodoor ${ }^{2}$, Mohammad Alqudah ${ }^{3}$, Amr Masaadeh ${ }^{3}$, \\ Marwa Barukba ${ }^{3}$, Rowida Almomani ${ }^{1}$
}

\begin{abstract}
Objective: TIMAP expression is regulated by transforming growth factor beta 1 (TGF $\beta 1$ ); known for its role in breast cancer development and metastasis. Nevertheless, data on TIMAP protein expression and its association with breast cancer development are lacking. In this study, we aimed to investigate the variation in TIMAP protein expression in breast cancer tissue and its correlation with various clinicopathological characteristics of breast cancer patients and overall survival rate. Methods: A total of 159 paraffin-embedded tissue blocks from women diagnosed with four breast cancer subtypes (49 HER2-only, 33 Luminal A, 39 Luminal B, and 38 triple negative) were used to construct tissue microarray (TMA), followed by TIMAP immunohistochemistry (IHC). TIMAP expression was scored by two pathologists and categorized as weak (1-33\% expression), moderate (34-66\%), and strong (67-100\%). Chi-square test and Kaplan Meier survival test were performed to determine the association between TIMAP expression and clinicopathological features and overall survival rate, respectively. Results: TIMAP protein was strongly expressed in 46 (93.9\%) HER2-only, 32 (97\%) luminal A, 37 (94.9\%) luminal B, and 29 (76.3\%) triple negative. TIMAP expression negatively associated with $E R / P R$ expression $(\mathrm{P}=0.03)$, and it negatively impacted the overall survival in HER2 negative group $(\mathrm{P}=0.02)$. Conclusion: Our findings suggest that TIMAP protein expression is upregulated in all breast cancer subtypes. However, its prognostic role is exclusively observed in HER2- negative group, suggesting a potential of targeting TIMAP in future therapeutic strategies in this group.
\end{abstract}

Keywords: PPP1R16B- HER2- ER-PR

Asian Pac J Cancer Prev, 22 (6), 1899-1905

\section{Introduction}

TIMAP (TGF $\beta$-Inhibited Membrane-Associated Protein); or as annotated in GenBank PPP1R16B, is a regulatory subunit of protein phosphatase 1 catalytic subunit (PP1c) predominantly expressed in central nervous system (CNS) and hematopoietic cell lines (Cao et al., 2002; Magdaleno et al., 2002). It regulates PP1c enzymatic activity by targeting the holoenzyme to specific subcellular locations and substrates; subsequently affecting target signal transduction cascades involved in controlling various cell processes (Boratkó and Csortos, 2017). For example, it binds and regulates the phosphorylation state of the non-integrin laminin receptor1 (LAMR1) (Kim et al., 2005); best known for its association with tumor progression, metastasis (Fülöp and Larbi, 2002), and tumor angiogenesis (Iwamoto et al., 1996). In addition, TIMAP interacts with and regulates the function of many other key molecules involved in controlling cell adhesion, survival, proliferation and migration. Among these molecules are myosin light chain 2 (MLC2) (Shopik et al., 2013;Wang et al., 2019) and Ezrin- Radixin- Moesin (ERM) family (Csortos et al., 2008; Boratkó and Csortos, 2017) that stimulate dynamic remodeling of cell cytoskeleton during cell adhesion, proliferation and migration. Another example is the eukaryotic elongation factor-1A (eEF-1A) (Boratkó et al., 2015), which exhibits roles in cytoskeleton organization, apoptosis, and regulation of protein expression (Sasikumar et al., 2012). Moreover, TIMAP has been shown to regulate the phosphorylation level and subcellular localization of merlin (Boratkó et al., 2017); a tumor suppressor known for regulating cell proliferation (Morrison et al., 2001) and organizing cellular junctions (McClatchey and Fehon, 2009). Also, TIMAP inhibits the tumor suppressor (PTEN)-mediated suppression of Akt activity in human endothelial cells (Obeidat et al., 2014). Akt activation is key to promoting cell survival, proliferation, angiogenesis, and tumor progression. On the other hand, PTEN antagonizes Akt effects, and thus is inhibited in many tumors. Altogether, these studies suggest

${ }^{1}$ Department of Medical Laboratory Sciences, Jordan University of Science and Technology, Irbid, Jordan. ${ }^{2}$ Department of Applied Biology, Jordan University of Science and Technology, Irbid, Jordan. ${ }^{3}$ Department of Pathology, Jordan University of Science and Technology, Irbid, Jordan. *For Correspondence: mmobeidat82@just.edu.jo 
that TIMAP might play an important role in cancer.

TIMAP is down regulated by transforming growth factor beta (TGFß1) (Cao et al., 2002; Yang et al., 2017) which is well known for its role in regulating various cellular processes, including proliferation, apoptosis, migration, angiogenesis, differentiation, inflammation, and cell cytoskeletal remodeling (Clark and Coker, 1998). Furthermore, TGF- $\beta$ is a key player in cancer development, and it is the main stimulator of epithelialto-mesenchymal transition (EMT); a cellular process that potentiates cancer cell metastasis (Garcia et al., 2018). TGF $\beta$ is an important regulator of normal mammary gland development, as well as breast cancer development and progression (Burdette et al., 2005), where it plays a dual role (Huang et al., 2018); while in early stages of mammary carcinogenesis it acts as a tumor suppressor, in late stages it promotes tumor progression by potentiating tumor metastasis (Muraoka et al., 2002; Nam et al., 2008). Hence, it's plausible to hypothesize that TIMAP expression might be altered in breast cancer.

Large scale mutagenesis analyses in mice sensitized to c-Myc-induced apoptosis identified TIMAP as one of key cellular oncogenes (Mendrysa et al., 2010). Moreover, according to RNA sequencing data, TIMAP expression appears to be altered in different solid tumors, including breast cancer, and hematological malignancies [https:// www.proteinatlas.org/ENSG00000101445-PPP1R16B/ pathology]. These data also indicated that it acts as a prognostic biomarker in head and neck and cervical cancers. However, to date, TIMAP expression at protein level and its role in breast cancer, or any kind of cancer for that matter, have not been studied.

In the current study, we investigated TIMAP protein expression in 159 breast cancer tissue samples categorized into the following subtypes; Human epidermal growth factor receptor 2 (HER2)-only, Luminal A, Luminal B, and triple negative, by immunohistochemistry (IHC) using tissue microarray (TMA) and correlated its protein expression with different clinicopathological features and overall survival rate.

\section{Materials and Methods}

Tissue specimens. A total of 159 women diagnosed with various breast cancer subtypes were identified via retrospective analysis of the pathological records from the department of pathology at King Abdullah University Hospital (Irbid, Jordan). The patients had been treated with radical mastectomy for the tumor or axillary lymph node resection between the years 2007 and 2019. This study was approved by the Faculty of Medicine Research Ethics Committee at Jordan University of Science and Technology (Irbid, Jordan).

TMA and IHC. Archived paraffin-embedded breast carcinoma tissue blocks were used to construct the TMA using TMA Master II instrument (3DHISTECH Ltd., Budapest, Hungary). TMA tissue blocks were sectioned at $4 \mu \mathrm{m}$ thickness and collected on Superfrost plus glass slides for processing by IHC using the BenchMark ULTRA system (Roche Diagnostics, Risch-Rotkreuz, Switzerland) as previously described (Bodoor et al., 2018;
Bodoor et al., 2020). Rabbit polyclonal antibody against TIMAP/PPP1R16B (MyBioSource, Inc, San Diego, USA) at 1:200 dilution was used to determine TIMAP protein expression. The slides were scored as described previously (Bodoor et al., 2018; Bodoor et al., 2020), whereas slides with $1-33 \%$ expression were scored as weak and were considered negative in statistical analysis; slides with $34-66 \%$ expression were scored as moderate and were considered positive; and slides with $67-100 \%$ expression were scored as strong and were also considered as positive in statistical analysis. The expression of Estrogen receptor (ER), Progesterone receptor (PR) and HER2 was retrieved from the patients archived records. Tumor volume was calculated differently according to available data for dimensions; For one- dimension $\mathrm{x}$ : volume $=$ $4 / 3 * \pi^{*}(\mathrm{x} / 2) 3$; for two dimensions $\mathrm{x}$ and $\mathrm{y}$ whereas $\mathrm{x}<\mathrm{y}$ : volume $=\mathrm{x} 2 * \mathrm{y}$; and for three dimensions $\mathrm{x}, \mathrm{y}$ and $\mathrm{z}$ : volume $=\mathrm{x}^{*} \mathrm{y}^{*} \mathrm{z}$.

Statistical Analysis. The relationship between TIMAP expression level and clinicopathological characteristics was established by Chi-square test. One-sided Fisher's exact test was considered more reliable for $2 \times 2$ crosstabs and thus was reported instead of Chi-square test where appropriate. Survival outcomes, defined as the period from time of diagnosis to death from any cause or the last contact, were estimated with the Kaplan Meier analysis and compared between groups by log-rank test. Statistical analyses were conducted using IBM SPSS Statistics for IOS, Version 26 (IBM Corp, Armonk, NY, USA). p-value $\leq 0.05$ was considered significant.

\section{Results}

Patients clinicopathological characteristics and TIMAP expression levels. The clinicopathological characteristics of the 159 study subjects are shown in Table 1. Specimens of four molecular subtypes of breast cancer were included in the study; 49 HER2-only (ER-/ PR-/ HER2+), 33 luminal A (ER+/PR+/HER2-), 39 luminal $\mathrm{B}(\mathrm{ER}+/ \mathrm{PR}+/ \mathrm{HER} 2+)$, and 38 triple negative (ER-/PR-/ HER2-). TIMAP expression was scored according to percentage of positive cells (as described in the methods section), and it was categorized into "negative" for both null and weak expression; and "positive" for both moderate and strong expression (Figure 1). Positive TIMAP expression was found in 46 (93.9\%) HER2-only subtype, 32 (97\%) luminal A subtype, 37 (94.9\%) luminal B subtype, 29 (76.3\%) triple negative subtype (Table 2). $78.6 \%$ of samples exhibited both cytoplasmic and nuclear expression of TIMAP, while $17 \%$ and $4.4 \%$ had a dominant nuclear and cytoplasmic expression, respectively (Table 2 and Figure 2).

Associations between TIMAP expression and clinicopathological characteristics of patients. Analyses of association between TIMAP expression and clinicopathological features of patients are displayed in Table 2. There was no significant association with most of the features. However, significant associations were observed between TIMAP expression and the molecular subtypes of breast cancer ( $\mathrm{p}=0.007), E R / P R$ expression $(\mathrm{P}=0.03)$, and TIMAP subcellular localization $(\mathrm{P}=0.000)$. 
Table 1. Clinicopathological Characteristics of Breast Cancer Patients Included in This Study $(n=159)$.

\begin{tabular}{|c|c|c|c|}
\hline Characteristics & Group & $\mathrm{N}$ & $\%$ \\
\hline \multirow[t]{3}{*}{ Age } & Mean (Range) & $51.3(28-82)$ & \\
\hline & $</=50$ & 78 & 49.1 \\
\hline & $>50$ & 81 & 50.9 \\
\hline \multirow[t]{2}{*}{ Histologic Grade } & I, II & 49 & 31.2 \\
\hline & III & 108 & 68.8 \\
\hline \multirow[t]{4}{*}{ Tumor Size } & $\mathrm{T} 1$ & 8 & 5.1 \\
\hline & $\mathrm{T} 2$ & 82 & 52.2 \\
\hline & $\mathrm{T} 3$ & 49 & 31.2 \\
\hline & $\mathrm{T} 4$ & 18 & 11.5 \\
\hline \multirow{4}{*}{$\begin{array}{l}\text { Lymph Node } \\
\text { Status }\end{array}$} & No & 40 & 27.6 \\
\hline & N1 & 30 & 20.7 \\
\hline & $\mathrm{N} 2$ & 31 & 21.4 \\
\hline & $\mathrm{N} 3$ & 44 & 30.3 \\
\hline \multirow[t]{2}{*}{ Metastasis } & M0 & 74 & 55.2 \\
\hline & M1 & 60 & 44.8 \\
\hline \multirow[t]{4}{*}{ Tumor Stage } & I & 4 & 3.1 \\
\hline & II & 40 & 30.8 \\
\hline & III & 26 & 20 \\
\hline & IV & 60 & 46.2 \\
\hline \multirow[t]{2}{*}{ Axillary Lymph } & Negative & 39 & 26.7 \\
\hline & Positive & 107 & 73.3 \\
\hline \multirow{2}{*}{$\begin{array}{l}\text { Vascular } \\
\text { Invasion }\end{array}$} & Negative & 32 & 25.6 \\
\hline & Positive & 93 & 74.4 \\
\hline \multirow[t]{2}{*}{ Family History } & Negative & 57 & 60.0 \\
\hline & Positive & 38 & 40.0 \\
\hline \multirow{4}{*}{$\begin{array}{l}\text { Molecular Sub- } \\
\text { types }\end{array}$} & HER2-only & 49 & 30.8 \\
\hline & Luminal A & 33 & 20.8 \\
\hline & Luminal B & 39 & 24.5 \\
\hline & Triple Negative & 38 & 23.9 \\
\hline \multirow[t]{5}{*}{ Histologic Types } & IDC & 125 & 86.2 \\
\hline & Basal/like & 6 & 4.1 \\
\hline & Metaplastic & 3 & 2.1 \\
\hline & Medullary & 6 & 4.1 \\
\hline & Micropapillary & 5 & 3.4 \\
\hline \multirow[t]{2}{*}{ DCIS } & Absent & 21 & 17.9 \\
\hline & Present & 96 & 82.1 \\
\hline \multirow[t]{3}{*}{ Treatment } & Chemotherapy & 39 & 33.1 \\
\hline & Adjuvant Chemotherapy & 76 & 64.4 \\
\hline & Hormone Therapy & 3 & 2.5 \\
\hline
\end{tabular}

IDC, Invasive Ductal carcinoma; DCIS, Ductal Carcinoma In Situ.

It is worth mentioning that there was a positive association between TIMAP expression and HER2 expression (61 cases in HER2 negative group and 83 in HER2 positive), however, it did not reach statistical significance $(\mathrm{P}=0.06)$, while TIMAP expression negatively associated with $E R / P R$ expression (75 cases in ER/PR negative group and 69 in $\mathrm{ER} / \mathrm{PR}$ positive, $\mathrm{P}=0.03$ ).

Associations between TIMAP expression and survival outcomes. We next investigated the impact of TIMAP expression on overall survival. There was no significant difference between negative and positive TIMAP expression when all subtypes were pooled together
Table 2. Association between TIMAP Expression and Clinicopathological Features of Breast Cancer Patients

\begin{tabular}{|c|c|c|c|c|c|}
\hline Characteristic & Group & Negative & Positive & Total & $\mathrm{P}$ value \\
\hline \multirow[t]{2}{*}{ Age } & $\leq 50$ & 8 & 69 & 78 & 0.4 \\
\hline & $>50$ & 1 & 80 & 81 & \\
\hline \multirow{4}{*}{$\begin{array}{l}\text { Molecular } \\
\text { Subtypes }\end{array}$} & HER2-only & 3 & 46 & 49 & $0.007 *$ \\
\hline & Luminal A & 1 & 32 & 33 & \\
\hline & Luminal B & 2 & 37 & 39 & \\
\hline & Triple Negative & 9 & 29 & 38 & \\
\hline \multirow[t]{2}{*}{ ER/PR } & ER-/PR- & 12 & 75 & 87 & $0.03 *$ \\
\hline & $\mathrm{ER}+/ \mathrm{PR}+$ & 3 & 69 & 72 & \\
\hline \multirow[t]{2}{*}{ HER2 } & Negative & 10 & 61 & 71 & 0.06 \\
\hline & Positive & 5 & 83 & 88 & \\
\hline \multirow{3}{*}{$\begin{array}{l}\text { Histologic } \\
\text { Grade }\end{array}$} & I & 0 & 8 & 8 & 0.3 \\
\hline & II & 2 & 39 & 41 & \\
\hline & III & 12 & 96 & 108 & \\
\hline \multirow[t]{4}{*}{ Tumor Size } & $\mathrm{T} 1$ & 0 & 8 & 8 & 0.3 \\
\hline & $\mathrm{T} 2$ & 7 & 75 & 82 & \\
\hline & $\mathrm{T} 3$ & 5 & 44 & 49 & \\
\hline & $\mathrm{T} 4$ & 2 & 16 & 18 & \\
\hline \multirow{4}{*}{$\begin{array}{l}\text { lymph Node } \\
\text { Status }\end{array}$} & No & 6 & 34 & 40 & 0.4 \\
\hline & N1 & 2 & 28 & 30 & \\
\hline & N2 & 4 & 27 & 31 & \\
\hline & N3 & 3 & 41 & 44 & \\
\hline \multirow[t]{2}{*}{ Metastasis } & M0 & 8 & 66 & 74 & 0.6 \\
\hline & M1 & 4 & 56 & 60 & \\
\hline \multirow[t]{4}{*}{ Tumor Stage } & I & 0 & 4 & 4 & 0.8 \\
\hline & II & 5 & 35 & 40 & \\
\hline & III & 3 & 23 & 26 & \\
\hline & IV & 4 & 56 & 60 & \\
\hline \multirow{2}{*}{$\begin{array}{l}\text { Axillary } \\
\text { Lymph }\end{array}$} & Negative & 5 & 34 & 39 & 0.7 \\
\hline & Positive & 9 & 98 & 107 & \\
\hline \multirow{2}{*}{$\begin{array}{l}\text { Vascular } \\
\text { Invasion }\end{array}$} & Negative & 3 & 29 & 32 & 0.5 \\
\hline & Positive & 7 & 86 & 93 & \\
\hline \multirow{2}{*}{$\begin{array}{l}\text { Family } \\
\text { history }\end{array}$} & Negative & 4 & 53 & 57 & 0.9 \\
\hline & Positive & 4 & 34 & 38 & \\
\hline \multirow[t]{2}{*}{ DCIS } & Absent & 2 & 19 & 21 & 0.9 \\
\hline & Present & 10 & 86 & 96 & \\
\hline \multirow{5}{*}{$\begin{array}{l}\text { Histologic } \\
\text { Types }\end{array}$} & IDC & 9 & 116 & 125 & \\
\hline & Basal/like & 1 & 5 & 6 & 0.4 \\
\hline & Metaplastic & 0 & 3 & 3 & \\
\hline & Medullary & 1 & 5 & 6 & \\
\hline & Micropapillary & 1 & 4 & 5 & \\
\hline \multirow[t]{3}{*}{ Location } & Nuclear & 3 & 24 & 27 & $0.000 *$ \\
\hline & Cytoplasmic & 4 & 3 & 7 & \\
\hline & Both & 8 & 117 & 125 & \\
\hline \multirow[t]{3}{*}{ Treatment } & Chemotherapy & 4 & 35 & 39 & 0.64 \\
\hline & $\begin{array}{l}\text { Adjuvant } \\
\text { Chemotherapy }\end{array}$ & 5 & 73 & 78 & \\
\hline & $\begin{array}{l}\text { Hormone } \\
\text { Therapy }\end{array}$ & 0 & 2 & 2 & \\
\hline
\end{tabular}

* p-value $\leq 0.05$ was considered significant.

(Figure $3 \mathrm{~A}, \mathrm{P}=0.3$ ), as well as when each subtype was analysed independently (Figure $3 \mathrm{~B}$ (HER2- only); $\mathrm{P}=0.75$, 3C (Luminal B); $\mathrm{P}=0.6$, 3D (Triple negative); $\mathrm{P}=0.3$ ). However, since TIMAP expression was negatively and 

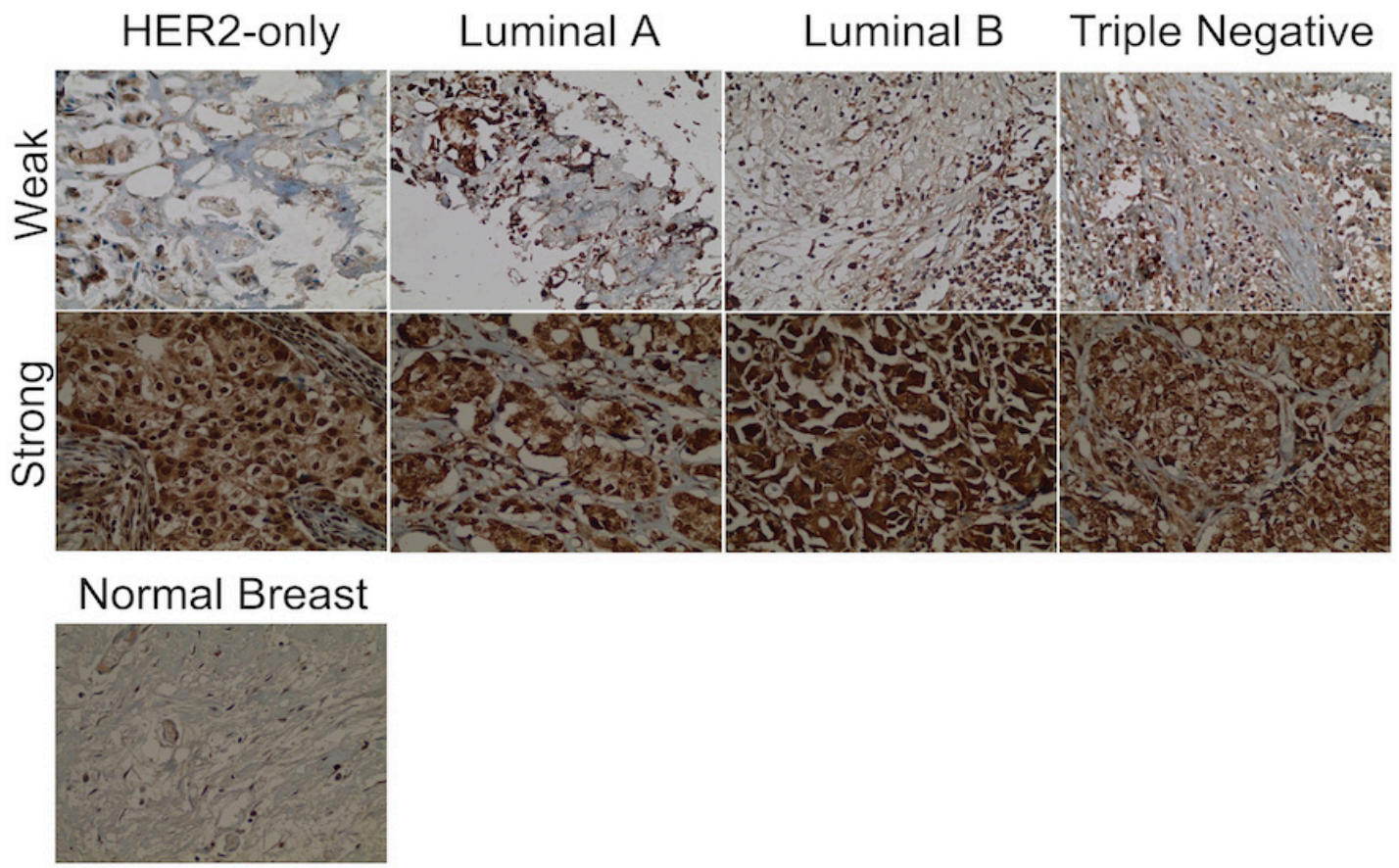

Figure 1. Immunohistochemical Images of TIMAP Expression in Breast Cancer Subtypes at 40X Magnification. Weak represents a negative expression and strong represents a positive expression. Normal breast tissue is a negative control.

positively correlated with $E R / P R$ and $H E R 2$ expression, respectively (Table 2), we further investigated its impact on overall survival in those groups. While there was no significant difference between negative and positive TIMAP expression among ER/PR negative (Figure 4A, $\mathrm{P}=0.3$ ), ER/PR positive (Figure $4 \mathrm{~B}, \mathrm{P}=0.6$ ), and HER2 positive groups (Figure $4 \mathrm{C}, \mathrm{P}=0.5$ ); there was a negative impact of TIMAP expression on overall survival in HER2 negative group (Figure 4D, $\mathrm{P}=0.02$ ).

\section{Discussion}

Previous transcriptome studies of different cancer cohorts have shown that TIMAP is upregulated in various tumor types, whereas it acts as a prognostic marker in both cervical and head and neck cancers [https:// www.proteinatlas.org/ENSG00000101445-PPP1R16B/ pathology]. However, to date, immunohistochemical data of TIMAP expression in cancer tissue and its clinical significance are lacking. Here, we present a novel evidence of TIMAP protein expression in breast cancer tissue.

In our study, TIMAP expression was significantly augmented in all subtypes of breast cancer compared to normal breast tissue, which showed minimal to no TIMAP expression (Figure 1). This result is consistent with previous studies that demonstrated a hematopoietic and central nervous system (CNS)- predominant expression of TIMAP in normal tissue (Cao et al., 2002; Magdaleno et al., 2002), and that its expression, at least at transcript level,

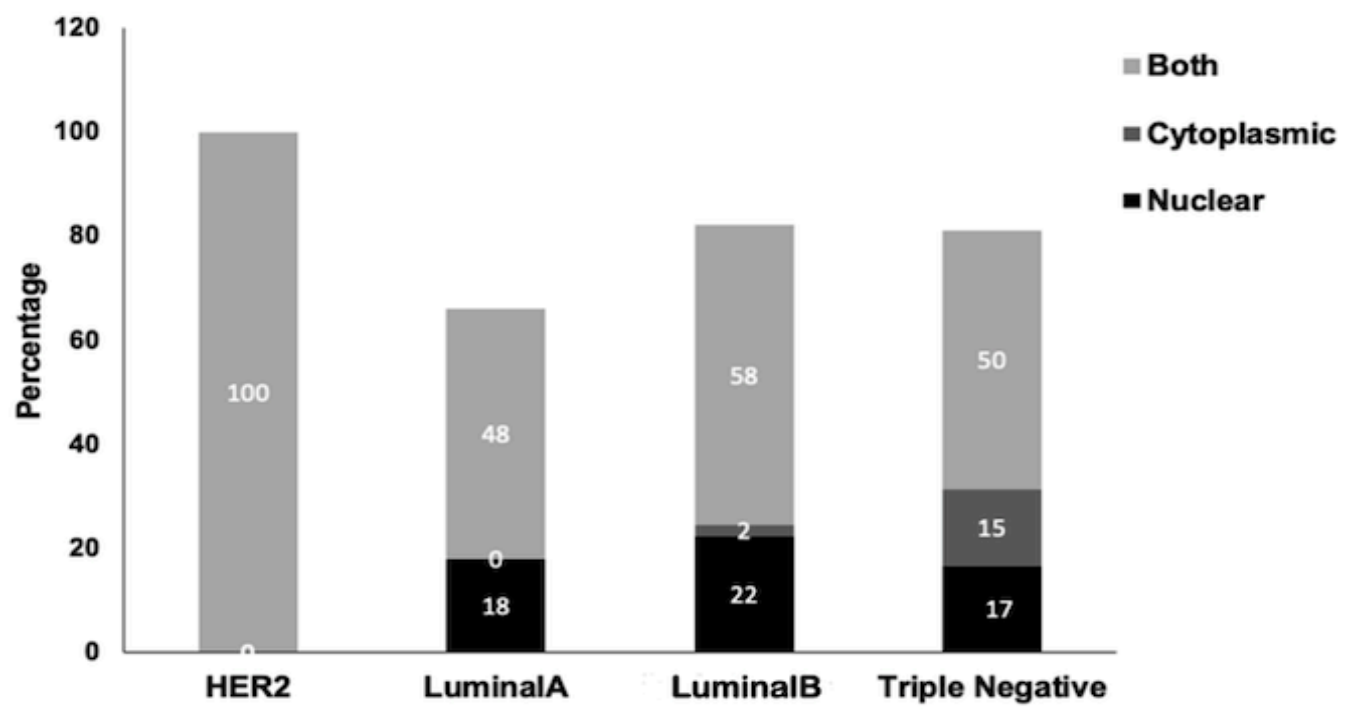

Figure 2. Percentage of Breast Cancer Samples Expressing TIMAP in Nucleus, Cytoplasm or Both. 
A

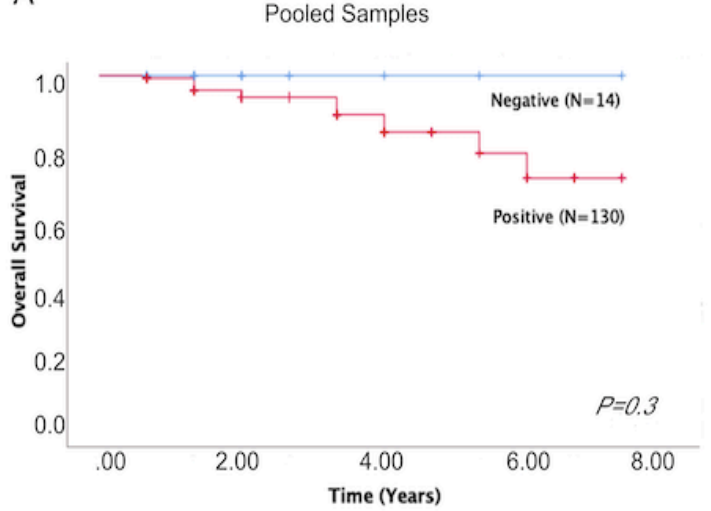

C

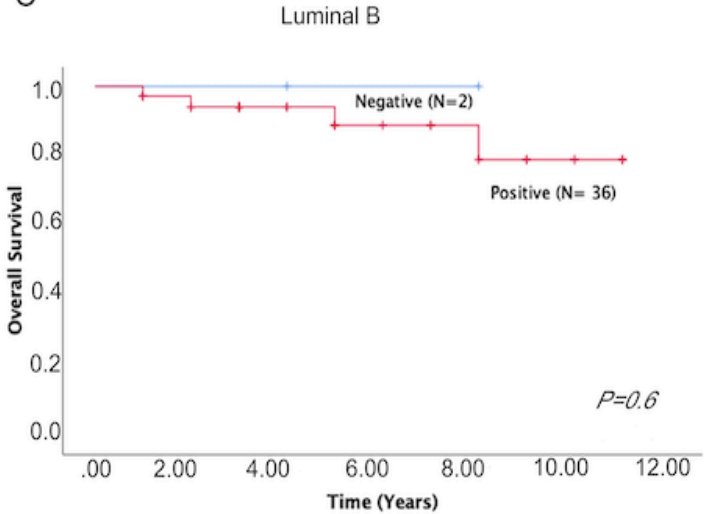

B

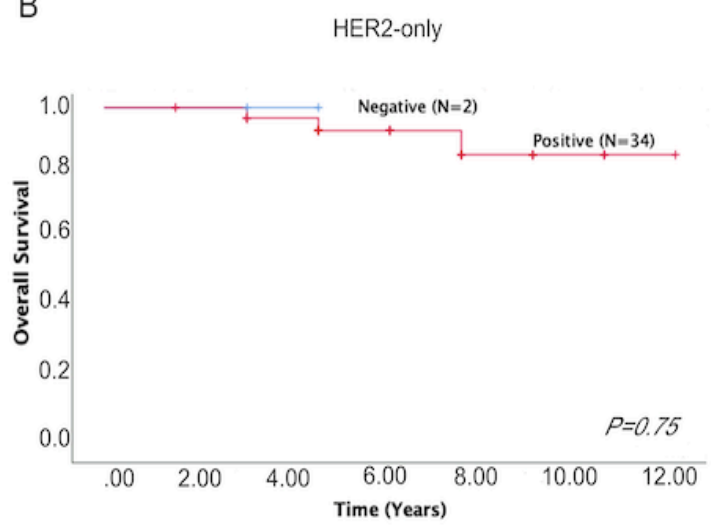

D

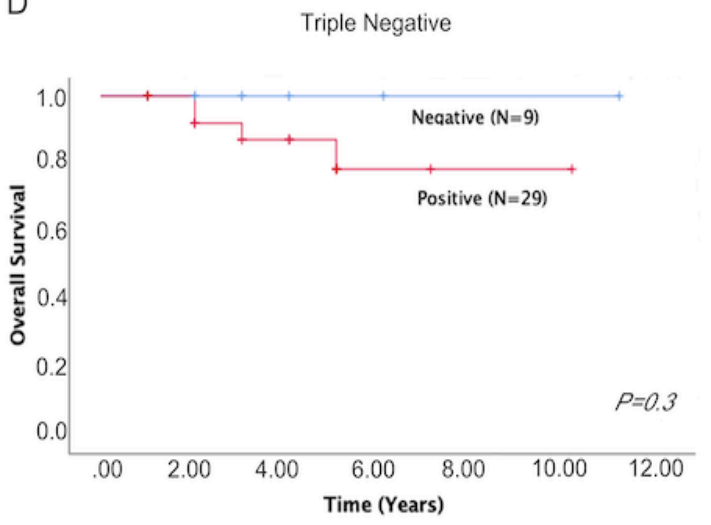

Figure 3. Overall Survival Analysis Based on TIMAP Expression in Pooled Samples and Different Breast Cancer Subtypes. A). Overall survival based on TIMAP expression in pooled samples. B). Overall survival based on TIMAP expression in HER2-only. C). Overall survival based on TIMAP expression in Luminal B. D). Overall survival based on TIMAP expression in triple negative.
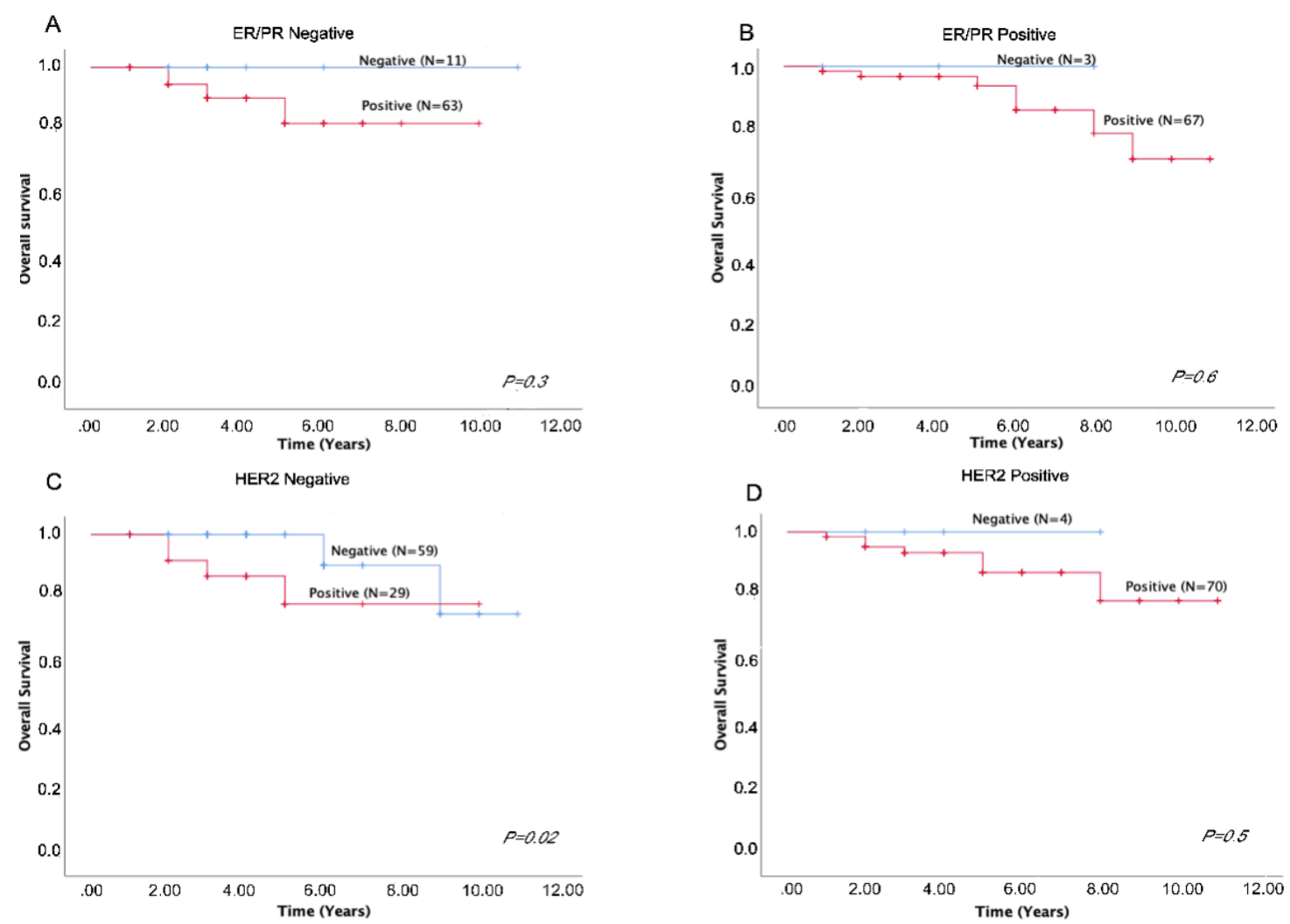

Figure 4. Overall Survival Analysis Based on TIMAP Expression in ER/PR and HER2 Negative and Positive Groups. A). Overall survival based on TIMAP expression in ER/PR negative group. B). Overall survival based on TIMAP expression in ER/PR positive groups. C). Overall survival based on TIMAP expression in HER2 negative groups. Overall survival based on TIMAP expression in HER2 positive groups. 
was upregulated in cancer [https://www.proteinatlas.org/ ENSG00000101445-PPP1R16B/pathology]. However, our study provides an unprecedented evidence of TIMAP upregulated expression at protein level in breast cancer.

Among the four subtypes studied here, TIMAP expression was observed less frequently in triple negative group, which is usually correlated with poor prognosis, while HER2-only, luminal A, and luminal B groups showed relatively similar and higher levels of expression. This result could not be directly related to the lack of expression of $E R, P R$, or $H E R 2$, as the non-triple negative subtypes express at least one of these proteins and show similar expression of TIMAP. However, since TIMAP has been shown to be downregulated by TGF $\beta 1$ (Cao et al., 2002; Yang et al., 2017) and that TGF $\beta 1$ is significantly upregulated in triple negative breast cancer as opposed to non-triple negative subtypes (Ding et al., 2016), it is plausible to suggest that the reduced level of TIMAP protein observed in the triple negative subtype here could be explained by presumably upregulated $T G F \beta 1$ expression. Nevertheless, future analyses are required to examine this possibility.

Furthermore, TIMAP expression was positively correlated with $H E R 2$ expression and negatively correlated with $E R / P R$ expression. Whether there is a regulatory relationship between these molecules is still unknown and requires further investigation. Nonetheless, since, overall, the prognosis of ER/PR-negative tumors is relatively poorer than for ER/PR-positive, targeting TIMAP may present a new therapeutic opportunity in treatment of challenging subtypes of breast cancer.

Most breast cancer samples in this study, regardless of their subtypes, displayed both cytoplasmic and nuclear expression patterns of TIMAP. This is in agreement with previous studies that showed TIMAP can be localized to the plasma membrane, cytoplasm and the nucleus (Cao et al., 2002; Kim et al., 2005; Li et al., 2007; Csortos et al., 2008; Boratkó et al., 2015; Boratkó and Csortos, 2017); and this is attributed to its N-terminal nuclear localization signal and the C-terminal CAAX domain (Cao et al., 2002) that allow TIMAP to shuttle between these cell compartments.

It has been previously shown that overexpression of TIMAP induces endothelial cell survival, proliferation and angiogenesis (Obeidat et al., 2014), as well as TGF $\beta 1$ - stimulated macrophage migration (Yang et al., 2017). Since these cellular processes are indispensable to tumor development and metastasis, we further analyzed whether TIMAP expression level was correlated with tumor development stage and metastasis state, however there was no significant correlation.

Our survival analysis demonstrated a clear negative impact of TIMAP expression in HER2-negative groups that are usually more resistant to treatment. This finding further highlights the potential role of TIMAP as a therapeutic target and, thus, we recommend future investigations to address the molecular mechanism of this protein in breast cancer development and the possibility of targeting it in the treatment of this disease, especially in drug resistant subtypes.

\section{Author Contribution Statement}

Marya Obeidat carried out the study design, examined the IHC staining, performed statistical analyses, drafted and prepared the final manuscript. Khaldon Bodoor participated in study design and helped in drafting and reviewing the manuscript. Mohammad Alqudah coordinated data collection and TMA and IHC staining, and pathological review of sections. Amro Masaadeh and Marwa Barukba scored the IHC staining and captured the microscopic images. Rowida Almomani participated in study design.

\section{Acknowledgements}

This study was approved by the Faculty of Medicine Research Ethics Committee and funded by the deanship of scientific research grant \# 20190103 at Jordan University of Science and Technology (Irbid, Jordan).

\section{Conflict of Interest}

The authors declare no proprietary or commercial interest in any product mentioned or concept discussed in this article.

\section{References}

Bodoor K, Abu-Sheikha A, Matalka IA, et al (2018). Immunohistochemical analysis of heat shock proteins in triple negative breast cancer: HSP60 expression is a marker of poor prognosis. Eur J Gynaecol Oncol, 39, 926-34.

Bodoor K, Almomani R, Alqudah M, Haddad Y, Samouri W (2020). LAT1 (SLC7A5) overexpression in negative her2 group of breast cancer: A potential therapy target. Asian Pac J Cancer Prev, 21, 253-8.

Boratkó A, Péter M, Thalwieser Z, Kovács E, Csortos C (2015). Elongation factor-1A1 is a novel substrate of the protein phosphatase 1-TIMAP complex. Int J Biochem Cell Biol, 69, 105-13.

Boratkó A, Veréb Z, Petrovski G, Csortos C (2016). TIMAPprotein phosphatase 1-complex controls endothelin-1 production via ECE-1 dephosphorylation. Int J Biochem Cell Biol, 73, 8-11.

Boratkó A, Péter M, Csortos C (2017). Regulation of merlin by protein phosphatase 1-TIMAP and EBP50 in endothelial cells. Int J Biochem Cell Biol, 82, 7-10.

Boratkó A, Csortos C (2017a). PKC mediated phosphorylation of TIMAP regulates PP1c activity and endothelial barrier function. Biochim Biophys Acta Mol Cell Res, 1864, 431-9.

Boratkó A, Csortos C (2017b). TIMAP, the versatile protein phosphatase 1 regulator in endothelial cells. IUBMB Life, 69, 918-28.

Burdette JE, Jeruss JS, Kurley SJ, et al (2005). Activin A mediates growth inhibition and cell cycle arrest through Smads in human breast cancer cells. Cancer Res, 65, 796875 .

Cao W, Mattagajasingh SN, Xu H, et al (2002). TIMAP, a novel CAAX box protein regulated by TGF- $\beta 1$ and expressed in endothelial cells. Am J Physiol Cell Physiol, 283, 327-37.

Clark DA, Coker R (1998). Transforming growth factor-beta (TGF- $\beta$ ). Int J Biochem Cell Biol, 30, 293-8.

Csortos C, Czikora I, Bogatcheva NV, et al (2008). TIMAP is a positive regulator of pulmonary endothelial barrier function. Am J Physiol Lung Cell Mol Physiol, 295, 440-50. 
Ding MJ, Su K, Cui GZ, et al (2016). Association between transforming growth factor- $\beta 1$ expression and the clinical features of triple negative breast cancer. Oncol Lett, 11, 4040-4.

Fülöp T, Larbi A (2002). Putative role of $67 \mathrm{kDa}$ elastin-laminin receptor in tumor invasion. Semin. Cancer Biol, 12, 219-29.

Garcia DA, Baek C, Valeria Estrada M, et al (2018). USP11 enhances TGFb-induced epithelial-mesenchymal plasticity and human breast cancer metastasis. Mol Cancer Res, 16, 1172-84.

Huang F, Shi Q, Li Y, et al (2018). HER2/EGFR-AKT signaling switches $\mathrm{TGFb}$ from inhibiting cell proliferation to promoting cell migration in breast cancer. Cancer Res, 78, 6073-85.

Iwamoto Y, Nomizu M, Yamada Y, et al (1996). Inhibition of angiogenesis, tumour growth and experimental metastasis of human fibrosarcoma cells HT1080 by a multimeric form of the laminin sequence Tyr-lle-Gly-Ser-Arg (YIGSR). $\mathrm{Br}$ $J$ Cancer, 73, 589-95.

Kim K, Li L, Kozlowski K, et al (2005). The protein phosphatase-1 targeting subunit TIMAP regulates LAMR1 phosphorylation. Biochem Biophys Res Commu, 338, 1327-34.

Li L, Kozlowski K, Wegner B, et al (2007). Phosphorylation of TIMAP by glycogen synthase kinase- $3 \beta$ activates its associated protein phosphatase 1. J Biol Chem, 282, 25960-9.

Magdaleno S, Northcutt GM, Curran T, Kurschner C (2002). mPPP1R16B is a novel mouse protein phosphatase 1 targeting subunit whose mRNA is located in cell bodies and dendrites of neurons in four distinct regions of the brain. Brain Res. Gene Expression Patterns, 1, 143-9.

McClatchey AI, Fehon RG (2009). Merlin and the ERM proteins - regulators of receptor distribution and signaling at the cell cortex. Trends Cell Biol, 19, 198-206.

Mendrysa SM, Akagi K, Roayaei J, et al (2010). An integrated genetic-genomic approach for the identification of novel cancer loci in mice sensitized to c-Myc-induced apoptosis. Genes Cancer, 1, 465-79.

Morrison H, Sherman LS, Legg J, et al (2001). The NF2 tumor suppressor gene product, merlin, mediates contact inhibition of growth through interactions with CD44. Genes Dev, 15, 968-80.

Muraoka RS, Dumont N, Ritter CA, et al (2002). Blockade of TGF- $\beta$ inhibits mammary tumor cell viability, migration, and metastases. J Clin Invest, 109, 1551-9.

Nam JS, Terabe M, Mamura M, et al (2008). An anti-transforming growth factor $\beta$ antibody suppresses metastasis via cooperative effects on multiple cell compartments. Cancer Res, 68, 3835-43.

Obeidat M, Li L, Ballermann BJ (2014). TIMAP promotes angiogenesis by suppressing PTEN-mediated Akt inhibition in human glomerular endothelial cells. Am J Physiol Renal Physiol, 307, 623-33.

Sasikumar AN, Perez WB, Kinzy TG (2012). The many roles of the eukaryotic elongation factor 1 complex. Wiley Interdiscip Rev RNA, 3, 543-55.

Shopik MJ, Li L, Luu HA, et al (2013). Multi-directional function of the protein phosphatase 1 regulatory subunit TIMAP. Biochem Biophys Res Commun, 435, 567-73.

Wang X, Obeidat M, Li L, et al (2019). TIMAP inhibits endothelial myosin light chain phosphatase by competing with MYPT1 for the catalytic protein phosphatase 1 subunit PP1c $\beta$. J Biol Chem, 294, 13280-91.

Yang J, Yin S, Bi F, et al (2017). TIMAP repression by TGF $\beta$ and HDAC3-associated Smad signaling regulates macrophage M2 phenotypic phagocytosis. J Mol Med, 95, 273-85.

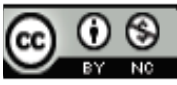

This work is licensed under a Creative Commons AttributionNon Commercial 4.0 International License. 